\title{
BIOENERGETICS OF GROWTH, PREGNANCY AND LACTATION IN THE LABORATORY MOUSE, MUS MUSCULUS
}

\author{
EUGENE H. STUDIER \\ Department of Biology, The University of Michigan-Flint, Flint, MI 48503, U.S.A.
}

(Receited 26 March 1979)

\begin{abstract}
Multiple regression models for reproductivity active (RA) female mice show bioenergetic parameters to be functions of total live weight of the reproducing unit and reproductive day but not related to litter size or daily weight gain.

2. For growing, non-reproductively active (NRA) females, bioenergetic parameters are linear functions of live weight.

3. Weight specific daily energy budgets are constant for RA and NRA females.

4. Productivity of RA females exceeds that of NRA mice reaching a peak at $10 \%$ at the end of lactation.

5. Weight spccific average daily metabolic rate of pregnant females is lower than that of NRA mice.
\end{abstract}

Energy budgets of individuals or populations of animals are frequently based on the tenet that ingested energy (I) is partitioned by organisms into assimilated energy (A) and non-used or waste energy (W), i.e. $\mathbf{I}=\mathrm{A}+\mathrm{W}$. Assimilated energy is further divisible into that used in metabolic maintenance or respiration $(R)$ and that resulting in growth or production $(P)$ i.e. $A=R+P$. Although a few field estimates of one or more aspects of energy budgets of ecological energetics during growth and reproduction of small mammals have been reported (Caldwell \& Connell, 1968; Mullen, 1971a,b; Collins \& Smith, 1976; Kunz, 1974; Anthony \& Kunz, 1977; Nagy et al., 1978), most bioenergetic studies have been performed with captive animals. Studies are available on a variety of small rodents (Kaczmarski, 1966; Gorecki, 1968, 1969, 1971, 1977; Drozdz, 1968; Trojan \& Wojciecjowski, 1969; Hansson \& Grodzinski, 1970; Drozdz et al., 1972; Gebczynski et al., 1972; Collier et al., 1975; French et al., 1975; Baar \& Fleharty, 1976; Ashby \& Vincent, 1976; Stueck et al., 1977; Randolph et al, 1977; Grodzinski et al., 1977) as well as other small mammals (Brisbin, 1966; Barrett, 1969; O'Farrell et al., 1971; Randolph, 1973). In most of these studies, ingested and waste energy were determined with assimilated energy obtained by difference. Respiratory energy demand has been calculated from somewhat theoretical considerations (McNab, 1963; Studier \& O'Farrell, 1976) or more frequently by intermittent measurement of metabolic rate but has scldom been estimated from continuous $24 \mathrm{hr}$ metabolism measurements. Although several studies concerning caloric density of dried mammalian tissue are published (Gorecki, 1965, Sawicka-Kapusta, 1970; Studier et al., 1973; Fedyk, 1974; Kaufman \& Kaufman, 1975; O'Farrell \& Studier, 1976), few bioenergetic studies utilize direct determination of growth or production. Additionally, although multiple regression models have been constructed for other systems (Newell \& Roy, 1973; Newell, 1975), this approach has apparently not been used in modelling mammalian energetics.
I report here a study in which ingested, waste, respiratory and production energy have been determined throughout growth, pregnancy and lactation in the laboratory mouse, Mus musculus. Multiple regression models of these various bioenergetic parameters have been constructed. Although several studies of certain components of ecological energetics of the laboratory mouse have been published (Myrcha \& Walkowa, 1968; Myrcha et al., 1969; Brisbin, 1970; Myrcha, 1975; Smith \& McManus, 1975), this species was chosen for study due to its ease of laboratory maintenance and its reproductive proclivity in captivity.

\section{MATERIAIS AND METHODS}

Young adult white laboratory mice from an inbred strain within a single population were studied. Only virgin mice were used. Mice were all kept and studied at a light cycle of $15 \mathrm{hr}$ light: $9 \mathrm{hr}$ dark with the light period beginning at 06:00 hr. For the purposes of this study, each day began at approximately 16:00 hr. Water in excess was provided to all mice in all phases of experimentation, and water consumption was not measured. Ambient temperature throughout the entire study period was maintained at $25^{\circ} \mathrm{C}$ with a variation of $\pm 2{ }^{\circ} \mathrm{C}$ in the animal room and $\pm 0.5^{\circ} \mathrm{C}$ in metabolism studies. During experimentation all mice were caged singly or with their offspring in plastic shoe box cages with wire mesh lids. Mice were fed only Purina Rat Chow throughout all phases of the experiment. Data were collected only on individual females or individual females together with their litter during lactation. Bedding of approximately one inch of vermiculite was routinely provided for all mice before experimentation. Day of pregnancy was determined by back counting from the day parturition except for pregnant mice used in calorimetry in which case day of pregnancy was estimated using the live weight to reproductive day relationship established for this population (see Results). Number of embryos were counted directly in mice killed during pregnancy or estimated as the number born in lactating females.

\section{Feeding experiments}

Feeding experiments were conducted in the animal room. Ingested and waste energy as well as total live 
weight changes were determined for young growing mice as well as pregnant and lactating individuals. Each feeding experiment was begun by placing a single weighed female (and her weighed young during lactation) into a standard shoe box cage in which a few pieces of paper towel were present for bedding. A weighed amount of food was provided. After $72 \mathrm{hr}$, remaining food was removed to obtain average food consumption for the three day period. Wastes were separated from bedding and the 3 day accumulation was freeze dried to constant weight to estimate average daily waste production. The female (together with her young when present) were weighed to estimate live weight change. Many non-pregnant, pregnant, and lactating mice together with their offspring were also freeze-dried to estimate growth increments on a dry weight basc. Threc day periods of study were used as a compromise to provide minimal disturbance to the experimental mice but not allow inordinately large growth increments.

\section{Metabolism experiments}

Individual non-pregnant, pregnant or lactating mice together with their offspring were weighed and placed in respirometers at about 16:00 hr. Food, water and bedding (vermiculite) were provided in the respirometers. Oxygen consumption was determined in an open flow system as described by Kaufman et al. (1975). An automatic switching device system allowed the continual determination of oxygen content flowing out of each of four successive respirometers for 13.5 continuous minutes (total of $54 \mathrm{~min}$ ) followed by a $6 \mathrm{~min}$ recording of inflowing oxygen level (20.8 vol\% oxygen) as a control and standardization for the system. Respirometers were glass dessicators equipped with lucite lids sealed with vacuum grease and held in place with lead bricks. Lids contained both air inlet and exit ports. Air flow was determined with a predictability flowmeter (Manostat Corp.) and regulated so that the in-out oxygen differential never exceeded 1.5 vol $^{\circ}$ oxygen. Twenty-four $13.5 \mathrm{~min}$ recordings were thus daily obtained for mice in the four chambers. Mice in chambers were again weighed at the end of the $24 \mathrm{hr}$. Weight specific oxygen consumption $\left(\mathrm{cm}^{3} \mathrm{~g} / \mathrm{hr}\right)$ corrected to STPD was then calculated using mean weight throughout the $24 \mathrm{hr}$ testing period

\section{Bomb calorimetry:}

After lyophilization to constant weight, food as well as wastc and carcasses of non-pregnant, pregnant and lactating mice plus embryos and neonates were individually ground to uniform consistency with a Micro-Mill (The Chemical Rubber Co., Cleveland, $\mathrm{OH}$ ). Embryo weights used throughout this study include both the weight of the embryos and placentae. Portions of the ground mixtures were pelleted in mixture with standardized benzoic acid and burned in a Parr oxygen bomb calorimeter (Model 1300) to determine energy content.

\section{Data analysis}

One on one stepwise polynomial regression analysis was performed on the energetic parameters (food, waste, respiratory and production energy) as dependent variables against weight, incremental weight change, reproductive day (RD), and litter size as single independent variables. Days during pregnancy were assigned negative values, e.g. day 6 before the day of parturition was day $=-6$. For purposes of these analyses, roots and powers of reproductive days retained their original sign so that for $\mathrm{RD}=-9$ $\mathrm{RD}^{2}=-81$, and $\sqrt{\mathrm{RD}}=-3$. Multiple regression models were constructed by stepwise backward elimination for each energetic parameter as possible functions of the previously mentioned independent variables in linear. root and power forms. Individual mouse number was also included as a categorical independent variable.
Table 1. Caloric equivalents of food, wastes and carcasses in reproductively active (RA) and non-reproductively active (NRA) laboratory mice

\begin{tabular}{llcl}
\hline \multicolumn{1}{c}{ Sample } & $N$ & kcal $/ \mathrm{g}$ dry weight & $\mathrm{SE}_{\boldsymbol{x}}$ \\
\hline Food & 12 & 4.365 & 0.011 \\
Wastes (RA) & 54 & 4.035 & 0.015 \\
Wastes (NRA) & 24 & 3.873 & 0.032 \\
Neonates & 24 & 5.418 & 0.050 \\
Embryos & 22 & 4.592 & 0.051 \\
Adults (RA) & 22 & 4.803 & 0.060 \\
Adults (NRA) & 27 & 5.170 & 0.064 \\
\hline
\end{tabular}

\section{RESULTS AND DISCUSSION}

\section{Caloric densities}

Pertinent caloric equivalents are given in Table 1. Food was $91.68 \%$ dry solids $\left(n=20 ; \mathrm{SE}_{\bar{x}}=0.04\right)$. For reproductively active (RA) mice, there was no relationship between caloric content of dried wastes and live weight or reproductive day (RD). Similarly, for non-reproductively active (NRA) females, there was no relationship between energy content of dried wastes and live weight. These possible relationships have apparently not been tested in other small rodents. The lack of a relationship between waste energy content and RD or weight indicates consistent relative assimilation of various macromolecular hydrolysis products and minerals in both RA and NRA females as a function of time. Dry wastes of RA mice yielded significantly more energy than dry wastes of NRA mice $(t=4.584 ;$ d.f. $=76 ; P<0.001)$. The difference in caloric density of wastes in RA and NRA females indicates differences in absorption of various hydrolysis products of macromolecules and/or minerals coincident with the onset of reproductive activity. With the exception of $S$. hispidus (Randolph et al., 1977), waste caloric equivalents reported in Table 1 are lower than other literature values for $M u s$ and other rodents (Kaczmarski, 1966; Migula, 1969; Myrcha et al., 1969; Drozdz et al., 1972; Gebczynski et al., 1972; Myrcha, 1975). This may be due partially to the fact that my values are for a combination of dry fecal and urinary wastes while most literature reports are for dry fecal wastes alone. For NRA rodents, there appears to be no relationship between caloric density of food eaten and wastes produced (Drozd7., 1968; Steuck et al., 1977).

Although there is a relationship between caloric density of embryos and neonates as a function of RD $(F=59.55 ;$ d.f. $=1$ and $34 ; P<0.001)$, there is no relationship between dry-weight-specific energy content of embryos alone and RD nor between caloric density of neonates alone and RD. Caloric equivalents were therefore calculated separately for embryos and neonates and did not need to be adjusted for RD. The possible relationship of embryonic caloric density to $\mathrm{RD}$ has apparently not been previously tested, although several papers deal directly or indirectly with the possible relation of neonatal caloric density as a function of age (Myrcha \& Walkowa, 1968; Brisbin, 1970; Sawicka-Kapusta, 1970, 1974; Fedyk, 1974: Kaufman \& Kaufman. 1975). Some of these authors reported a rapid increase in neonatal caloric density during the first few days of postnatal life and all found 
Table 2. Multiple regression models of bioenergetic parameters for reproductively active mice

\begin{tabular}{|c|c|c|c|c|c|c|c|}
\hline & & & & $F$ & d.f. & $P$ & $r^{2}$ \\
\hline (1) WT (g) & $\begin{aligned}= & -0.01023 \sqrt{ } R^{2} D^{2} \\
& ( \pm 0.00333)\end{aligned}$ & $\begin{array}{l}+2.017 \text { RD } \\
( \pm 0.191)\end{array}$ & $\begin{array}{l}+49.21 \\
( \pm 0.54)\end{array}$ & 667.95 & 2,164 & $<0.0001$ & 0.891 \\
\hline (2) DFE (g/day) & $=\begin{array}{c}0.7127 \sqrt{R D} \\
( \pm 0.1650)\end{array}$ & $\begin{array}{l}+0.1154 \mathrm{WT} \\
(+0.0253)\end{array}$ & $\begin{array}{l}+4.596 \\
(+1.269)\end{array}$ & 273.51 & 2.67 & $<0.0001$ & 0.891 \\
\hline (3) DWP (g/day) & $=\underset{( \pm 0.0700)}{0.3821 \sqrt{R D}}$ & $\begin{array}{l}+0.02925 \mathrm{WT} \\
( \pm 0.01076)\end{array}$ & $\begin{array}{c}+2.426 \\
( \pm 0.539)\end{array}$ & 233.12 & 2,67 & $<0.0001$ & 0.874 \\
\hline (4) $\mathrm{OC}(1 /$ day $)$ & $=\underset{( \pm 0.0372)}{0.2024 \sqrt{R D}}$ & $\begin{array}{l}+0.05359 \mathrm{WT} \\
( \pm 0.00606)\end{array}$ & $\begin{array}{c}+1.563 \\
( \pm 0.295)\end{array}$ & 348.78 & 2.85 & $<0,0001$ & 0.891 \\
\hline (5) DAG (g/day) & $=\begin{array}{r}0.1254 \sqrt{R D} \\
( \pm 0.0189)\end{array}$ & & $\begin{array}{c}+8.993 \\
( \pm 0.211)\end{array}$ & 43.82 & 1,42 & $<0.0005$ & 0.511 \\
\hline (6) DENG (g/day) & $=\begin{array}{c}0.02985 \sqrt{ } R^{2} \\
( \pm 0.00357)\end{array}$ & $\begin{array}{l}{ }^{2}+0.3740 \sqrt{R D} \\
( \pm 0.1622)\end{array}$ & $\begin{array}{l}+2.700 \\
( \pm 0.250)\end{array}$ & 212.14 & 2,48 & $<0.0001$ & 0.898 \\
\hline
\end{tabular}

Reproductive day (RD) retains its original sign ( + or -$)$ irrespective of its power transformation. Other abbreviations include $W T=$ total live weight: $D F E=$ dry food eaten: DWP $=$ dry wastes produced $; \mathrm{OC}=$ oxygen consumed $; \mathrm{DAG}=$ dry adult growth $: \mathrm{DENG}=$ dry embryonic or neonatal growth. Equation (1) was used to estimate day of pregnancy in individuals used for determination of caloric density of pregnant females and embryos.

constant caloric density of neonates extending from shortly after birth until weaning. In my investigation, caloric density of neonates is significantly higher than that of embryos $(t=161.93 ;$ d.f. $=44 ; P<0.001)$. Caloric density of animal tissue or whole carcasses is a direct function of fat abundance. The dichotomy between caloric density of embryos and neonates would thus seem attributable to constant but different levels of body fat in embryos and neonates. The rapid appearance of fat in neonates is probably the result of positive energy balance in the suckling young related to the high fat content of the mother's milk (Jenness \& Sloan, 1970). Caloric density of Mus embryos shown in Table 1 is markedly lower than the few values reported for other rodents (Fleharty et al., 1973) while those of neonates fall well within literature values for this and other rodent species (Myrcha \& Walkowa, 1968; Brisbin, 1970; Sawicka-Kapusta, 1970, 1974; Fedyk, 1974; Kaufman \& Kaufman, 1975; Randolph et al., 1977).

For RA adults, there is no relationship between caloric density of dry carcasses and RD or live weight. For NRA females, there is no relationship between dry energy content and live weight. Caloric density of NRA females is higher than dry-weight-specific energy content of RA females $(t=47.69$; d.f. $=47$; $P<0.001)$. The statements concerning fat abundance and caloric density applied previously to the discussion of embryonic and neonatal energy content also apply to RA and NRA females. I have been unable to locate literature on caloric density of RA females for comparison; however the value for NRA lab mice compares favorably with literature reports for rodents (Myrcha \& Walkowa, 1968; Sawicka-Kupusta, 1970; Hansson \& Grodzinski, 1970; Drozdz et al., 1972). An energy equivalent for oxygen consumption of $4.825 \mathrm{kcal} / \mathrm{l}$ was used (Guyton, 1976).

\section{Bioenergetic parameters}

Multiple regression models of the various bioenergetic parameters are given in Table 2. Linear, root and power transformations of daily live weight increments and litter size were not retained as significant independent variables in any analysis. The fact that litter size was not significantly related to food consumed, wastes produced, oxygen consumed or growth is rather surprising in view of the many literature reports of relationships of litter size to these bioenergetic parameters (Fedyk, 1974; Smith \& McManus, 1975; Winand et al. 1976; Koong \& Bradford, 1976; Nowosielski-Slepowron \& Park, 1974, 1976; Randolph et al., 1977). When total live weight of the reproducing unit, i.e. live weight of pregnant mice or combined live weight of lactating female and young, was not included as an independent variable, then litter size becomes a significant variable in multiple regression models of the various bioenergetic parameters. Since this is true, total live weight explains the variability attributable to litter size. Whenever possible, i.e. in food eaten, wastes produced, and oxygen consumption analyses, individual mouse number was included as a possible categorical variable. It was found to be significant in each analysis performed; however, it cannot be included in the models. Since individual mouse number is significant, variation between mice affects the predictability of the models. Based on their coefficients of determination $\left(r^{2}\right)$, regression models for bioenergetic parameters of RA mice (Table 2), with the exception of dry adult growth, are highly predictive. Approximately $90 \%$ of the variability in dry food eaten, dry wastes produced, oxygen consumption and dry embryonic or neonatal growth is attributable to weight and/or RD in RA mice.

Regression equations for bioenergetic parameters of NRA female mice are given in Table 3 . A value for dry growth rate $\left(0.0881 \mathrm{~g} / \mathrm{day} ; \mathrm{SE}_{\boldsymbol{x}}=0.0048 ; n=21\right)$ was calculated from average live weight increments of 21 NRA females for periods of 24 or 25 days and applying the following equation for the relationship of dry weight (DW in g) to live weight (LW in g) in NRA females:

$$
\begin{array}{rr}
\mathrm{DW}=0.3405 & \mathrm{LW}-1.045 \\
( \pm 0.0235) & ( \pm 0.577)
\end{array}
$$

where $F=209.1 ;$ d.f. $=1$ and $25, P<0.0001$; $r^{2}=0.893$ and the values in parentheses are standard errors. Based on coefficients of determination 
Table 3. Regression equations for bioenergetics parameters in mice which are non-reproductively active

\begin{tabular}{|c|c|c|c|c|c|}
\hline & & & $F$ & d.f. & $r^{2}$ \\
\hline (1) DFE (g/day) & $=\begin{array}{c}0.1791 \mathrm{WT} \\
( \pm 0.0232)\end{array}$ & $\begin{array}{c}+0.5091 \\
( \pm 0.4720)\end{array}$ & 59.37 & 1,137 & 0.302 \\
\hline (2) DPW (g/day) & $=\begin{array}{c}0.06055 \mathrm{WT} \\
( \pm 0.01021)\end{array}$ & $\begin{array}{l}+0.1707 \\
( \pm 0.2074)\end{array}$ & 35.14 & 1.137 & 0.207 \\
\hline (3) $O C$ (l/day) & $=\frac{0.06382 \mathrm{WT}}{( \pm 0.00609)}$ & $\begin{array}{c}+0.8657 \\
( \pm 0.1501)\end{array}$ & 109.80 & 1,107 & 0.507 \\
\hline
\end{tabular}

Abbreviations are the same as in Table $2(P<0.0001$ in all cases $)$.

(Table 3), the regression equations for NRA mice for their bioenergetic parameters are not reliably predictive and explain relatively little of the variability of the bioenergetic parameters.

\section{Daily energy budgets and efficiencies}

Using the equations given in Table 2 and the caloric equivalents from Table 1 , daily total and component energy budgets as well as various utilization efficiencies have been calculated (Table 4) for RA mice: In Table 4, item 6 is the sum of waste energy, oxygen consumption, adult growth energy and reproductive growth energy and should theoretically equal item 1 (food eaten). Item 7 is the ratio of item 6 to item 1. Daily energy budget is the range of weight specific total daily energy budget obtained by dividing item 6 by weight and item 1 by weight. Productivity is the range found by dividing the sum of adult growth energy and reproductive growth energy by items 1 and 6. Assimilation efficiency is the sum of oxygen consumption, adult growth energy and reproductive growth energy divided by items 1 and 6 . The ranges shown for metabolic efficiency and waste efficiency are the respective quotients of oxygen consumption and waste energy to items 1 and 6 .

There is apparently no statistically accurate method of summing the errors in waste energy, oxygen consumption, adult growth energy and reproductive growth energy to determine if that sum overlaps food eaten. Since waste energy, oxygen consumption, adult growth energy and reproductive growth energy, however, each show variability, the sum of these parameters would exhibit greater variability than that of food eaten alone, making food eaten the more accurate estimate of the bioenergetic requirements of RA mice. Throughout the period of reproductive activity food eaten is nearly accounted for by the sum of waste energy, oxygen consumption, adult growth energy and reproductive growth energy (see Table 4, item 7). Food eaten estimate may be slightly high because some powdered food from the original supply may not have been eaten and would be included in waste energy. This would result in an overestimate of waste energy which might offset the possible overestimate of food eaten on a dry weight basis. However, since food eaten caloric equivalent is higher than waste energy caloric equivalent (from Table 1; $t=17.74$; d.f. $=64 ; P<0.001$ ), equal dry weight errors would not yield equal caloric errors.

Many authors have reported daily energy budgets based on averaged daily metabolic rate adjusted for ambient temperature, activity patterns, body weight, grouping, etc. (Wiegert, 1961; McNab, 1963; Trojan \& Wojciechowska, 1967, 1969; Gorecki, 1968, 1969. 1971, 1977; Gebzynska, 1970; Hansson \& Grodzinski, 1970; Ashby \& Vincent, 1976; Baar \& Fleharty, 1976; French et al., 1976; Grodzinski et al., 1977). Adjusted average daily metabolic rate can actually represent total daily energy budget only if all food ingested is utilized, i.e. no wastes are produced, and if no growth

Table 4. Daily and component energy budgets and efficiencies for reproductively active white mice. Mus musculus

\begin{tabular}{|c|c|c|c|c|c|c|c|c|c|}
\hline RD & -20 & -15 & -10 & -5 & 0 & +5 & +10 & +15 & +20 \\
\hline WT & 11.62 & 21.00 & 30.37 & 39.75 & 49.14 & 58.52 & 67.90 & 77.28 & 86.65 \\
\hline 1. $\mathrm{FE}$ & 11.99 & 18.56 & 25.48 & 33.08 & 44.75 & 56.41 & 64.00 & 70.92 & 77.50 \\
\hline 2. WE & 4.28 & 6.31 & 8.51 & 11.04 & 15.60 & 20.15 & 22.68 & 24.88 & 26.91 \\
\hline 4. $\mathrm{AGE}$ & 0.60 & 0.60 & 0.60 & 0.60 & 0.60 & 0.60 & 0.60 & 0.60 & 0.60 \\
\hline 5. $\mathrm{RGE}$ & $-0-$ & $-0-$ & $0.46^{*}$ & 1.75 & 2.01 & 2.07 & 3.55 & 5.11 & 6.70 \\
\hline 8. DEB & $0.95-1.03$ & $0.77-0.88$ & $0.72-0.84$ & $0.73-0.83$ & $0.78-0.91$ & $0.76-0.96$ & $0.81-0.94$ & $0.80-0.92$ & $0.79-0.89$ \\
\hline 9. Pro & $5.0-5.4$ & $3.2-3.7$ & $4.2-4.8$ & $7.1-8.1$ & $5.8-6.8$ & 4.76 .0 & $6.5-7.6$ & $8.1-9.2$ & 9.410 .7 \\
\hline 10. AFf $\%$ & $56.4-61.2$ & $52.7-60.8$ & $52.4-61.1$ & 54.461 .9 & $51.1-59.4$ & 48.861 .1 & $50.5-58.8$ & $\$ 2.2-60.0$ & $53.7-60.7$ \\
\hline 11. MEf- $\%$ & $51.4-55.8$ & $49.5-57.1$ & $48.3-56.2$ & $47.2-53.8$ & $45.2-52.6$ & $44.0-55.6$ & $44.0-51.2$ & $44.1-50.6$ & $44.3-50.1$ \\
\hline 12. WEf $\%$ & $35.7-38.7$ & $34.0-39.2$ & $33.4-38.9$ & 33.438 .0 & $34.9-40.6$ & $35.7 \cdot 45.1$ & $35.4-41.2$ & $35.1-40.2$ & $34.7-39.3$ \\
\hline
\end{tabular}

Abbreviations used are $\mathrm{RD}=$ reproductive day: $\mathrm{WT}=$ total live weight: $\mathrm{FE}=$ ingested (food) energy; $\mathrm{WE}=$ waste energy; $\mathrm{OC}=$ metabolic energy; $\mathrm{AGE}=$ adult growth energy; $\mathrm{RGE}=$ embryonic and neonatal growth energy; $\mathrm{DEB}=$ total daily energy budget in $\mathrm{kcal} / \mathrm{g} / \mathrm{day} ;$ Pro $=$ productivity; $\mathrm{AEf}=$ assimilation efficiency; $\mathrm{MEf}=$ metabolic efficiency; $\mathrm{WEf}-$ wastc efficiency. Items $1-6$ are expressed in $\mathrm{kcal} / \mathrm{day}$. See text for further explanation.

* Estimate based on dry growth rate of $0.1 \mathrm{~g} / \mathrm{day}$. 
occurs during the period of measurement. Since these conditions do not occur in growing NRA rodents or RA rodents, daily energy budgets based on adjusted average daily metabolic rate represent absolute minimal maintenance requirements and are not comparable to daily energy budgets based on food eaten or the summation of waste energy, oxygen consumption, adult growth energy and reproductive growth energy.

Weight specific daily energy budgets of RA laboratory mice (Table 4 ) are relatively constant throughout pregnancy and lactation centering at $0.83 \mathrm{kcal} / \mathrm{g} /$ day, excluding RD of -20 . The high daily energy budget of $\mathrm{RD}=-20$ mice is probably due to the higher weight-specific oxygen consumption of these small females and will be discussed in more detail later. Smith \& McManus (1975) reported daily energy budgets based on food eaten for lactating laboratory mice of $0.748-1.033 \mathrm{kcal} / \mathrm{g} /$ day. Other daily energy budgets based on food eaten for RA rodents include $0.25-0.29 \mathrm{kcal} / \mathrm{g} /$ day for pregnant and lactating Sigmodon hispidus (estimated from Randolph et al., 1977 ); $0.46 \mathrm{kcal} / \mathrm{g} /$ day for lactating Clethrionomys glareolus (Gebczynski, 1975); and $0.49 \mathrm{kcal} / \mathrm{g} /$ day for pregnant Microtus arvalis (Migula, 1969). These lower values, particularly for Sigmodon, probably result from markedly lowered weight specific metabolic rates in these larger rodents.

Productivity is the fraction of total daily energy budget which is fixed as adult, embryonic and neonatal growth during a single day. Expressed as a percentage, these values rise toward the end of pregnancy, fall for the few days preceding and following parturition, and rise again toward the end of lactation (Table 4). Adult growth rate throughout the reproductive period was constant. Fluctuations in productivity observed during pregnancy and lactation, therefore, result from similar tissue growth patterns by embryos and neonates. Dry growth rate of embryos near the end of pregnancy and of newborns during the first few days of neonatal life is reduced when compared to the days just before and after this period. Part of the apparent reduction in growth around parturition is the loss of the fixed energy in the placentae at birth. A reduction of growth rate (expressed in terms of daily energy budget) around the time of parturition has been previously reported for RA rodents (Kaczmarski, 1966; Migula, 1969). Peak productivity during pregnancy reaches about $8 \%$ while during lactation peak productivity slightly $\epsilon$ Xceeds $10 \%$. These values are generally below productivity levels reported for other RA rodents (Kaczmarski, 1966; Migula, 1969; Gebczynski, 1975; Smith \& McManus, 1975). The disparity is probably due to the fact that these authors generally reported total productivity and not the daily rate of productivity. Also, if as discussed earlier, my food eaten estimates are slightly high, then my productivity estimates may be slightly low.

Assimilation efficiency is defined as the sum of oxygen consumption, adult growth energy and reproductive growth energy divided by gross total daily energy budget and expressed as a percentage. This remains constant for RA mice at an average of $56.5 \%$ throughout the entire reproductive period. This average assimilation efficiency may be slightly low if the food eaten level is over-estimated and will be a few percentage points lower than literature values for digestive efficiency where the urinary energy equivalents are taken into account. Several authors report no differences in assimilation efficiency or digestive efficiency during pregnancy and lactation in rodents (Kaczmarski, 1966; Migula, 1969; Randolph et al., 1977). Values for assimilation efficiency reported by these authors for other rodents are all markedly higher than the $56.5 \%$ reported here for Mus. Smith \& McManus (1975), however, reported assimilation efficiency of $69.5-72.5 \%$ for lactating laboratory mice.

The metabolic fraction of total daily energy budget averages $50.1 \%$. This ratio falls slightly throughout the reproductive period. It is obvious that the metabolic fraction (essentially equivalent to average daily metabolic rate) of total energy budget would have to be adjusted by a factor of about 2 to roughly equate to actual total daily energy budget.

The portion of the total daily energy budget which appears as combined waste energy averages $37.4 \%$ and remains constant throughout the period of reproductive activity. Since the assimilation fraction in these mice was markedly lower than other rodents as previously indicated, the waste efficiency is consequently higher than most previous reports for RA mice.

Table 5 shows daily total and component energy budgets and efficiencies as calculated from the equations in Table 3 and caloric equivalents from Table 1 for NRA mice in the approximate weight range of $10-40 \mathrm{~g}$. Although none of my NRA mice reached a weight of $40 \mathrm{~g}$, it is useful to include theoretical values for mice of that weight for comparison purposes. Pos-

Table 5. Total daily and component energy budgets and efficiencies for non-reproductively active mice at various live weights (WT)

\begin{tabular}{lcccc}
\hline WT & 11.62 & 21.00 & 30.37 & 39.75 \\
(1) FE & 11.31 & 18.64 & 25.96 & 33.30 \\
(2) WE & 3.39 & 5.59 & 7.79 & 19.99 \\
(3) OC & 7.75 & 10.64 & 13.53 & 16.42 \\
(4) AGE & 0.46 & 0.46 & 0.46 & 0.46 \\
(5) $\Sigma 2-4$ & 11.59 & 16.68 & 21.77 & 26.86 \\
(6) $5 / 1-\%$ & 102.56 & 89.51 & 83.85 & 80.66 \\
(7) DEB & $0.973-0.998$ & $0.794-0.888$ & $0.717-0.855$ & $0.676-0.838$ \\
(8) Pro- $\%$ & $3.9-4.0$ & $2.4-2.7$ & $1.8-2.1$ & $1.4-1.7$ \\
(9) AEf- $\%$ & $70.8-72.6$ & $59.5-66.5$ & $53.9-64.2$ & $50.7-62.8$ \\
(10) MEf $\%$ & $66.9-68.6$ & $57.1-63.8$ & $52.1-62.1$ & $49.3-61.1$ \\
(11) WEf- $\%$ & $29.2-29.9$ & $30.0-33.5$ & $30.0-35.8$ & $30.0-37.2$ \\
\hline
\end{tabular}

See Table 4 for abbreviations used. 
sible sources of error are similar to those in food eaten and waste energy indicated previously for RA mice. The sum of waste energy, oxygen consumption, and adult growth energy closely approximate food eaten.

For NRA mice of $10-40 \mathrm{~g}$., total daily energy budget averages $0.84 \mathrm{kcal} / \mathrm{g} /$ day but drops continually with increasing weight (Table 5). This decreasing daily energy budget is similar to the observed drop in metabolic efficiency with increasing weight and appears to be a function of decrease in weight-specific oxygen consumption with increasing weight. Further discussion of this point will follow. The average daily energy budget reported here for NRA female laboratory mice exceeds the $0.571 \mathrm{kcal} / \mathrm{g} /$ day found for this species by Smith \& McManus (1975) but agrees closely with values reported by Myrcha (1975). Literature values for other rodents (including all studies where daily energy budget was based on adjusted average daily metabolic rate) are generally lower than that found here (Hawkins \& Jewell, 1962; Kaczmarski, 1966; Trojan \& Wojciechowska, 1967; Drozdz, 1968; Gorecki, 1968, 1969, 1971; Migula, 1969, Hansson \& Grodzinski, 1970; Gebezynski, 1970, 1975; Drozdz et al., 1972; Gebczynski et al., 1972; Ashby \& Vincent, 1976; Baar \& Fleharty, 1976; Stueck et al., 1977; Randolph et al., 1977). Examination of the data of the authors just cited also shows a generalized decrease in weight specific daily energy budget with increasing weight.

In NRA female laboratory mice, productivity averages $2.5 \%$ of the total daily energy budget and drops continually with increasing weight of growing individuals in the weight range of $10-40 \mathrm{~g}$. Although productivity in these NRA mice is understandably lower than reported annual productivity in rodents (Ashby \& Vincent, 1976; Gorecki, 1977), it agrees well with values found in growing individuals (Migula, 1969) as well as decreasing productivity with increasing weight in individual rodents (Drozdz et al. 1972).

The assimilated fraction of food eaten in NRA females drops progressively with increasing weight and averages $62.6 \%$ of the total daily energy budget. On the other hand, Myrcha (1975) found increasing assimilation efficiency with increasing weight in NRA females and Drozdz et al. (1972) found no change in assimilation efficiency with increasing weight. Assimilation efficiency of NRA females slightly exceeds that of RA females of equivalent weight, whereas $\mathrm{Kacz}^{-}$ marski (1966) and Migula (1969) found no differences in assimilation efficiency of RA and NRA females. Great variability in assimilation efficiency are reported (Drozdz, 1968; Gebczynski, 1970) for NRA rodents which nearly all exceed the value found for NRA laboratory mice in this study.
As mentioned earlier, metabolic efficiency drops throughout the growth of NRA mice from $10-40 \mathrm{~g}$. Metabolic efficiency averages $60.1 \%$ of total daily energy budget thus accounting for a $10 \%$ greater fraction of total daily energy budget than in RA females. Again, however, average daily metabolic rate as reflected by metabolic efficiency would have to be adjusted markedly upward to provide an estimate of total daily energy budget. The metabolic efficiency reported here is considerably lower than those calculated from the data of Myrcha (1975) for this species although Myrcha also showed decreasing metabolic efficiency with increasing weight.

Waste efficiency remains essentially constant at $32.0 \%$ of total daily energy budget throughout this growth period in NRA females.

Table 6 shows a comparison of calculated total daily food eaten for a 40 day period of normal growth in NRA females compared to that of RA mice assuming identical initial weights. The ratio of food eaten (RA) to food eaten (NRA) then provides some estimate of the energy costs of reproduction relative to those of growth. Although there is no difference in average weight specific energy costs of RA $(0.83 \mathrm{kcal} /$ $\mathrm{g} /$ day) and NRA $(0.84 \mathrm{kcal} / \mathrm{g} /$ day $)$ females, there is a marked increase in total food eaten by RA mice (as a total reproductive unit) compared to NRA mice. This increase in food eaten is due directly to the relative increase in total live weight of the reproducing unit (i.e. the pregnant female or the lactating female plus her young). The increased requirements of RA females is much more rapid during the first 20 days of comparison than during the later days. Associated with the rise in absolute food eaten during pregnancy and lactation is a concommitant increase in the length and absorptive capacity of the gut of RA females, particularly evident during lactation (Fell et al., 1963; Sanders \& Morgan, 1957; Adams et al., 1976). Peak increases in food requirements during pregnancy $(291 \%)$, and lactation $(399 \%)$ greatly exceed comparable literature reports for this (Myrcha et al., 1969; Smith \& McManus, 1975) and other rodent species (Kaczmarski, 1966; Migula, 1969; Baar \& Fleharty, 1976; Randolph et al., 1977).

The productivity of RA mice greatly exceeds that of NRA females. Since weight specific daily energy budgets are identical in both RA and NRA females, the greater productivity of RA mice must be explained by differences in partitioning of food eaten. Throughout the weight range for NRA growing mice, this difference in partitioning is represented by different weight specific metabolic rates as shown in Fig. 1. The weight specific metabolic rates of NRA females is greater than that of RA females in the weight range from about $10-45 \mathrm{~g}$. This lowered metabolic rate of $\mathrm{RA}$

Table 6. Calculated food energy (FE) requirements in Kcal/day of non-reproductively active (NRA) and reproductively active (RA) lab mice beginning at the same weight. Live growth rate for NRA mice is $0.259 \mathrm{~g} /$ day

\begin{tabular}{lrrrrrrrrr}
\hline RD & -20 & -15 & -10 & -5 & 0 & +5 & +10 & +15 & +20 \\
WT NRA) & 11.62 & 12.92 & 14.21 & 15.51 & 16.80 & 18.10 & 19.39 & 20.70 & 21.98 \\
FE(NRA) & 11.31 & 12.31 & 13.31 & 14.36 & 15.36 & 16.37 & 17.33 & 18.42 & 19.42 \\
WT(RA) & 11.62 & 21.00 & 30.37 & 39.75 & 49.14 & 58.52 & 67.90 & 77.28 & 86.65 \\
FE(RA) & 11.99 & 18.56 & 25.48 & 33.08 & 44.75 & 56.41 & 64.00 & 70.92 & 77.50 \\
RA/NRA & 1.06 & 1.51 & 1.91 & 2.30 & 2.91 & 3.45 & 3.69 & 3.90 & 3.99 \\
\hline
\end{tabular}




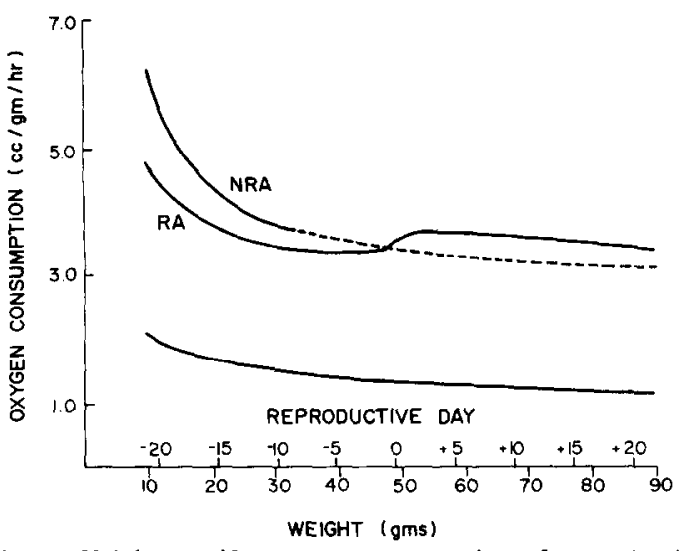

Fig. 1. Weight specific oxygen consumption of reproductively active (RA) and non-reproductively active (NRA) mice as functions of total weight. The lower (unlabeled) line represents the relationship of weight specific oxygen consumption to weight for mammals under basal conditions (i.e. $\mathrm{OC}=3.8 \mathrm{WT}^{0.27}$ where WT is in $\mathrm{g}$, from Morrison et al., 1959). Approximate RD is shown for RA mice.

females allows a greater fraction of food eaten to be directed toward productivity. Since neither RA nor NRA females are at basal conditions, it is not surprising that the relation of metabolic rate to weight in both are considerably greater than the minimum relationship for mammals (lower line in Fig. 1). The asymptotic curvature of all three lines is consistent with the predicted relationships based on similar decreases in surface area: mass ratio with increasing body weight. It is the high metabolic rates associated with high surface area: mass ratios of small RA and NRA females which accounts for the high daily energy budgets and metabolic efficiencies of such individuals as presented earlier. The rise in metabolic rate at parturition in RA mice is also apparently the result of the instantaneous increase in the surface area: mass ratio of the reproducing unit concommitant with parturition. Similar reasoning explains the observation in Fig. 1 that weight specific metabolic rates during lactation remain higher than the projected line for NRA individuals.

Since young mice are ectothermic for nearly two weeks post partum (Lagerspetz, 1962) and since together the neonates comprise a significant portion of the biomass of the reproducing unit throughout lactation, it is surprising that the metabolic rate during lactation is indicative of endothermic organisms with no apparent change in metabolic rate when the neonates, in fact, become endothermic. As shown by Gebczynski (1975), the presence of the mother in the nest makes the metabolic rate of offspring relatively independent of ambient temperature which may account for the endothermic-like metabolic rates of the reproducing unit during lactation.

\section{SUMMARY}

Daily energetic parameters, i.e. food eaten, combined wastes produced, oxygen consumed, as well as adult, embryonic and neonatal growth rates have been determined for young, growing NRA female laboratory mice and for RA mice throughout preg- nancy and lactation. Dry weight caloric density has been ascertained for food, combined wastes and the carcasses of embryos, neonates, RA and NRA adult female mice.

1. For RA mice caloric density of dried wastes are not related to RD or total live weight of the reproducing unit. For NRA mice caloric density of dried wastes are not related to live weight. Caloric density of dried wastes of RA mice is higher than that of NR $\Lambda$ females.

2. Caloric density of dried carcasses of neither neonates nor embryonic mice is related to RD. Dry caloric density of neonates exceeds that of embryos.

3. Among adult females, dry caloric density of NRA individuals is higher than that of RA individuals. Therc is no rclationship between dry caloric density of the carcasses of RA mice and RD or total live weight of the reproducing unit nor for NRA females and live weight.

4. Multiple regression models have been constructed for RA mice for the various bioenergetic parameters as possible linear, root or power functions of $\mathrm{RD}$, total live weight of the reproducing unit, litter size and daily live weight increments as well as individual nouse number as a categorical variable.

5. For RA mice, the bioenergetic parameters are shown to be functions of RD, total live weight of the reproducing unit and mouse number. Litter size was a significant independent variable only when weight was not included among the independent variables; therefore, total weight of the reproducing unit explains the variability attributable to litter size. Although it cannot be included in the multiple regression models, individual mouse number is significant and, therefore, variation between mice affects the predictability of the models.

6. Similar multiple regression models for NRA mice include live weight as the only significant independent variable.

7. Weight specific daily average energy budgets of RA and NRA females are not different $(0.83$ and $0.84 \mathrm{kcal} / \mathrm{g} /$ day, respectively).

8. Productivity in RA mice is a direct function of embryonic and neonatal growth rate fluctuations reaching peaks of 8 and $10 \%$ of total daily energy budgets in late pregnancy and lactation, respectively. Productivity in NRA mice progressively decreases with increasing live weight and is markedly lower than productivity of RA mice.

9. The average daily metabolic rates for both RA and NRA females comprises about half of their total daily energy budgets.

10. Weight specific average daily metabolic rates of NRA females is greater than that of RA (pregnant) feriales of the same weight. Weight specific average daily metabolic rates of RA mice during lactation show no change at the onset of endothermy in neonates and are higher than projected values for NRA mice.

Acknowledgements-All initial phases of this study wero conducted at the Savannah River Ecology Laboratories Aiken, South Carolina, through funding by an NSF Faculty Research Participation Grant (Contract No. EY-76-C-09-0819). I thank Linda L. Lawrence for her help in all initial phases of this study and Jerone $T$. Landström 
for aid in the later calorimetry determinations. Dr Richard W. Dapson provided many useful comments on the manuscript and many useful discussions of statistical treatment of data. Ted Herzog ran most of the computer programs and his aid is gratefully acknowledged.

\section{REFERENCES}

Adams S. A. Ajam 1. K., Matthews B. F.\& Sullivan P. B. (1976) Increased gastric emptying and intestinal motility in lactating mice. J. Physiol. 257, 57-58P.

Anthony E. L. P. \& Kunz T. H. (1977) Feeding strategies of the little brown bat, $M$ yotis lucifugus, in southern New Hampshire. Ecology 58, 775-786.

ASHBY K. R. \& VINCENT M. A. (1976) Individual and population energy budgets of the water vole. Acta theriol. 21, 499-512.

BaAr S. L. \& Fleharty E. D. (1976) A model of the daily energy budget and energy flow through a population of the white-footed mouse. Acta theriol. 21, 179-193.

BARRETT G. W. (1969) Bioenergetics of a captive least shrew. Cryptotis parva. J. Mammal. 59, 629-630

BRISBIN I. L. JR (1966) Energy utilization in a captive hoary bat. J. Mammal., 47, 719-720.

BRISBIN 1. L. JR (1970). A determination of live-weight caloric conversation factors for laboratory mice. Ecology 51, 541-544.

Caldwell L. D. \& Connell C. E. (1968) A precis on energetics of the old-field mouse. Ecology 49, 542-548.

Collier B. D., Stenseth N. C., Barkley S. \& Osborn R. (1975) A simulation model of energy acquisition and utilization by the brown lemming Lemmus trimucronatus at Barrow, Alaska. Oikos 26, 276-294.

Collins V. R. \& Sмiтh M. H. (1976) Field determination of energy flow in a small nocturnal mammal. J. Mammal 57, $149-158$.

DROZDZ A. (1968) Digestibility and assimilation of natural foods in small rodents. Acta theriol 13, 367-389.

Drozdz A. Gorecki A. \& Sawicka-Kapusta K. (1972) Bioenergetics of growth in common voles. Acta theriol. 17, 245-257.

FEDYK A. (1974) Gross body composition in postnatal development of the bank vole. I. Growth under laboratory conditions. Acta theriol. 19, 381-401.

Fell B. F., Smith K. A. \& Campbell R. M. (1963) Hypertrophic and hyperplastic changes in the alimentary canal of the lactating rat. J. Path. Bact. 85, 179-188.

Fleharty E. D.. Krausf M. E. \& Stinnett D. P. (1973) Body composition, encrgy content and lipid cycles of four species of rodents. J. Mammal. 54, 426438

French N. R., Grant W. E., Grodzinski W. \& Swift D. M. (1976) Small mammal energetics in grassland ecosystems. Ecology 46, 201-220.

GebCZynsKa $Z$. (1970) Bioenergetics of a root vole population. Acta theriol. 15, 33-66.

GEBCZYNSKI M. (1975) Heat economy and the energy cost of growth in the bank vole during the first month of postnatal life. Acta theriol. 20, 379.434.

Gebczynski M., Gorecki A. \& Drozdz A. (1972) Metabolism, food assimilation and bioenergetics of three species of dormice (Gliridae). Acta theriol. 17, 271-294.

GORECKI A. (1965) Fnergy values of body in small mammals. Acta theriol. 10, 333-352.

GoRECKI A. (1968) Metabolic rate and energy budget in the bank vole. Acta theriol. 13, 341--365.

GoRECKI A. (1969) Metabolic rate and energy budget of the striped field mouse. Acta theriol. 14, 181-190.

GorECKI A. (1971) Metabolism and energy budget in the harvest mouse. Acta theriol. 16, 213-220.

GoreCKI A. (1977) Energy flow through the common hamster population. Acta theriol 22, 25-66.

Grodzinski W., Makomaska M., Tertil R. \& Weiner J. (1977) Bioenergetics and total impact of vole populations. Oikos 29, 494 510 .
Guyton A. C. (1976) Textbook of Medical Physiology. 5th edn., XXXVI + 1194 pp. Saunders, Philadelphia.

Hansson L. \& GrodzinSKI W. (1970) Bioenergetic parameters of the field vole Microtus aurestis L. Oikos 21 , $76-82$.

Hawkins A. E. \& Jewell P. A. (1962) Food consumption and energy requirements of captive British shrews and mole. Proc. Zool. Soc. Lond. 138, 137-155.

Jenness R. \& Sloan R. E. (1970) The composition of milks of various species: a review. Dairy Sci. Abstr. 32 , 599-612.

KACZMARSKI F. (1966) Bjoenergetics of pregnancy and lactation in the bank vole. Acta theriol. 11, 409-417

Kaufman D. W. \& Kaufman G. A. (1975) Caloric density of the old-field mouse during postnatal development. Acta theriol. 20, 83-95.

Kaufman D. W. Kaufman G. A. \& Smith G. C. (1975) Oxygen consumption in Ord's kangaroo rat. Tex. J. Sci. 26, 615-618.

KoONG L-J. \& BRADFORD G. E. (1976) Effects of stage of gestation and litter size on prenatal growth in the mouse. Anim. Prod. 22, 225-230.

KUNZ T. H. (1974) Feeding ecology of a temperate insectivorous bat (Myotis velifer). Ecology 55, 693-711.

MCNAB B. K. (1963) A model of the energy budget of a wild mouse. Ecology 44, 521-532.

Migula P. (1969) Bioenergetics of pregnancy and lactation in European common vole. Acta theriol. 14, 167-179.

Morrison P., Ryser F. A. \& DAwE R. (1959) Studies on the physiology of the masked shrew. Sorex cinereus. Physiol. Zool. 32, 256-271.

Mullen R. K. (1971a) Energy metabolism and body water turnover rates in two species of free-living kangaroo rats. Dipodomys merriami and Dipodomis microps. Comp. Biochem. Physiol. 39A, 379 -390.

Mullen R. K. (1971b) Energy metabolism of Peromyscus crinitus in its natural environment. $J$. Mammal. 52, 633- 635 .

M YRChA A. (1975) Bioenergetics of an experimental population and individual laboratory mice. Acta theriol. 20 , 175-226.

Myrcha A. \& Walkowa W. (1968) Changes in the caloric value of the body during the postnatal development of white mice. Acta theriol. 13, 391-400.

MYRCHA A., RYSZkOWSKI L. \& WaLkowa W. (1969) Bioenergetics of pregnancy and lactation in white mouse. Acta theriol. 14, 161-166.

Nagy K. A., Seymour R. S., Lee A. K. \& Braithwaite R. (1978) Energy and water budgets in free-living Antechinus stuartii (Marsupalia: Dasyuridae). J. Mammal. 59, $60-68$.

NEWELL R. C. (1975) Factors controlling metabolic capacity adaptation in marine invertebrates. pp. 111-127. In Pysiological Ecology of Estuarine Organisms (Edited by VernberG J. F.), pp. 111-127. University of South Carolina Press, Columbia.

Newell R. C. \& Roy A. (1973) A statistical model relating the oxygen consumption of a mollusk (Littorina littorea) to activity, body size, and environmental conditions. Physiol. Zool. 46, 253- 275.

Nowosielski-Slepowron B. J. A. \& PARK A. W. (1974) The criteria of litter size in relation to growth of the rat. I. The influence of numbers. Acta morph. Ne'erl.-scand. 12. $299-316$

Nowosielski-Slepoworn B. H. A. \& PARK A. W. (1977) The criteria of litter size in relation to growth of the rat. II. Maternal capacity and stimulation. Acta morph. Neerl-scand. 15, 203-223.

O'Farrell M. J. \& STudier E. H. (1976) Cyclical changes in flight characters, body composition and organ weights in Myotis thysanodes and $M$. lucifugus (Chiroptera: Vespertilionidael. Bull. S. Calif. Acad. Sci.75, $258-266$.

O'Farrfil. M. J.. Stidile E. H. \& Ewing W. G. (1971) 
Energy utilization and water requirements of captive Myotis thysanodes and Myotis lucifugus (Chiroptera). Comp. Biochem. Physiol. 39A, 549-552.

RANDOLPH J. C. (1973) Ecological energetics of a homeothermic predator, the short-tailed shrew. Ecology 54, $1166-1187$

Randolph P. A., Randolph J. C., Mattingly K. \& FosTER M. M. (1977) Energy costs of reproduction in the cotton rat. Sigmodon hispidus. Ecology 58, 31-45.

SAwICKA-Kapusta K. (1970) Changes in the gross body composition and the caloric value of the common voles during their postnatal development. Acta theriol. 15, 67.79.

Sawicka-Kapusta K. (1974) Changes in the gross body composition and cnergy valuc of the bank vole during their postnatal development. Acta theriol. 19, 27-54.

Smith B. W. \& McManus J. J. (1975) The effects of litter size on the bioenergetics and water requirements of lactating Mus musculus. Comp. Biochem. Physiol. 51A, $111-115$.

Souders H. J. \& Morgan A. F. (1957) Weight and composition of organs during the reproductive cycle in the rat. Am. J. Physiol. 191, 1-7.

Studier E. H. \& O'Farrell M. J. (1976) Biology of Myotis thysanodes and M. lucifugus (Chir optera: Vesper-
tilionidae)--III. Metabolism, heart rate, breathing rate, evaporative water loss and general energetics. Comp. Biochem. Physiol. 54A, $423-432$.

Studier E. H., LySEnGen V. L. \& O'Farrell M. J. (1973) Biology of Myotis thysanodes and $M$. lucifugus (Chiroptera: Vespertilionidae)--II. Bioenergetics of pregnancy and lactation. Comp. Biochem. Physiol. 44A, 467471.

Stueck K. L., Farrell M. P. \& G. W. Barrett. (1977) Ecological energetics of the golden mouse based on three laboratory diets. Acta theriol. 22, 309-315.

Trojan P. \& Wuntchowska B. (1967) Resting metabolism rate during pregnancy and lactation in the European common vole--Microtus arvalis (Pall.). Ekol. pol. A. 44, 811-817.

Trojan P. \& WojciechowsKa B. (1969) Ecological model and tables of the daily energy costs of maintenance (DEB) of Microtus arvalis (Pall.). Ekol. pol. A. 17, 313-329.

WIEGERT R. G. (1961) Respiratory energy loss and activity patterns in the meadow vole, Microtus pennsylvanicus pennsylvanicus. Ecology 42, 245-253.

Winand J., Hebbelinck M., Wodon C. \& Cristophe J. (1976) Influence of litter size on lipid composition in infant mice. Nutr. Metab. 20, 289-301. 